\title{
Comparison of Diagnostic Criteria to Detect Undiagnosed Diabetes in Acute Coronary Syndrome Patients with Admission Hyperglycemia
}

\author{
Mohammad Sarwar Alam¹, HI Lutfur Rahman Khan², Abdul Wadud Chowdhury², \\ Khandker Md. Nurus Sabah², Md Gaffar Amin ${ }^{2}$, SM Eftar Jahan Kabir ${ }^{1}$, Abu Sadique Abdullah ${ }^{3}$, \\ Mofazzal Hossain ${ }^{4}$, Tunaggina Afrin Khan ${ }^{5}$, Md Sk Shahidullah ${ }^{6}$ \\ ${ }^{1}$ Department of Cardiology, National Institute of Cardiovascular diseases, ${ }^{2}$ Department of \\ Cardiology, Dhaka Medical College, Dhaka. ${ }^{3}$ Department of Cardiology, Bangabandhu Sheikh Mujib \\ Medical University, ${ }^{4}$ Dhaka, Upazilla Health Complex, Basail, Tangail, ${ }^{5}$ Department of Cardiology, \\ Anowar khan Modern Medical College \& Hospital, ${ }^{6}$ Department of Microbiology, OSD, DGHS.
}

\begin{abstract}
:
Key Words : Acute Coronary Syndrome, Fasting blood sugar, Admission plasma sugar, Oral glucose tolerance test, Glycated haemoglobin, Coronary artery disease, Diabetes mellitus.

Background: Diabetes mellitus is one of the most important risk factors of coronary artery disease. Admission hyperglycemia adversely influences the outcome of acute coronary syndrome patients. The study was conducted to compare the various diagnostic methods for the detection of undiagnosed diabetes mellitus in acute coronary syndrome patients with admission hyperglycaemia in Bangladeshi population.

Methods: It was a cross sectional comparative study involving 157 patients with admission blood glucose level e"7.8 mmol/l. Fasting plasma glucose, Glycated haemoglobin, pre-discharge oral glucose tolerance test was measured in all subjects and comparison of performance of different methods was done.

Results: Oral glucose tolerance test revealed that in spite of admission hyperglycaemia, 57 (36.3\%) patients were diabetic and $52(33.12 \%)$ patients had impaired glucose homeostasis and 48 (30.57\%) patients had normal glucose metabolism. Undiagnosed diabetes could not be adequately predicted with admission plasma glucose, fasting plasma glucose or HbAlc alone (area under the ROC curve $0.589,0.825$ and 0.852 respectively).

Conclusion: Admission hyperglycaemia does not diagnose diabetes reliably in a stressful condition like acute coronary syndrome. Although neither admission plasma glucose, fasting plasma glucose, nor HbAlc level were as good as oral glucose tolerance test in detecting true diabetes, but combined fasting plasma glucose \& HbAlc were found to be more sensitive \& specific screening tool for detecting unknown diabetes in acute coronary syndrome patients with admission hyperglycaemia.
\end{abstract}

(Cardiovasc.j. 2015; 8(1): 35-42)

\section{Introduction:}

Cardiovascular disease and Diabetes mellitus are two closely related diseases. In patients with both stable and unstable coronary artery disease $(\mathrm{CAD})$, there is a high prevalence of diabetes and increased rates of both undiagnosed diabetes and impaired glucose metabolism such as impaired glucose tolerance (IGT) or impaired fasting glucose (IFG)..$^{1,2}$ Cardiovascular disease is currently the leading cause of death worldwide. ${ }^{3}$ At the same time, there is a worldwide epidemic of diabetes mellitus, with over 280 million (6.4\%) of the world's population affected. ${ }^{4}$
According to the Diabetes Atlas 2010, India had 51 million diabetics in 2010 compared to 7 million in Pakistan, 6 million in Bangladesh, 27 million in the US and 43 million in China. The epidemic of diabetes is projected to continue unabated. By 2030 this is projected to increase to 87 million in India, 14 million in Pakistan, 10 million in Bangladesh, 36 million in the US and 63 million in China. ${ }^{4}$

Traditionally, diagnosis of diabetes was based on symptoms due to hyperglycaemia, but during the last decades much emphasis has been placed on

Address of Correspondence: Dr. Mohammad Sarwar Alam, Department of Cardiology, National Institute of Cardiology, Dhaka, Bangladesh. Email-sarwarrmc@gmail.com 
the need to identify diabetes and other forms of glucose abnormalities in asymptomatic subjects.

Elevated plasma glucose levels on admission (APG) are common in patients admitted with acute coronary syndromes (ACS) and are associated with a high incidence of adverse clinical outcomes, particularly compared with patients with normoglycaemic ACS. ${ }^{5-8}$ Nevertheless, hyperglycaemia remains unrecognized and untreated in a considerable portion of patients with ACS. ${ }^{9}$ Clinicians may consider an elevated APG as a parameter of the temporary physical stress that is a natural part of and caused by the ACS which will normalize once the coronary event is adequately managed. It should be realized, however, that elevated APG can also be a sign of hitherto unrecognized diabetes mellitus. In this respect, the lack of knowledge of an elevated APG is of concern as the prevalence of undiagnosed diabetes will be underestimated. ${ }^{10}$

The European Society of Cardiology and the European Association for the Study of Diabetes (EASD) already advocate investigating glucose metabolism in patients without known diabetes but with established cardiovascular disease through an oral glucose tolerance test (OGTT). ${ }^{11}$ However, a recent survey in the Netherlands showed that $76 \%$ of cardiologists do not routinely measure HbA1c prior to discharge in patients with ACS. ${ }^{9}$ With this in mind, it is unlikely that the more labour-intensive OGTT is standard care in daily cardiology practice. ${ }^{6}$

A substantial number of ACS patients get admitted in the Cardiology Department of Dhaka Medical College Hospital with admission hypergylcaemia. The aim of the study is to compare different diagnostic methods for detecting undiagnosed diabetes mellitus in ACS patients with admission hyperglycaemia .

\section{Methods:}

It was a cross sectional comparative study carried out in the department of Cardiology, Dhaka Medical College Hospital (DMCH), Dhaka during the period of May, 2012 to April, 2013. All the patients of Acute Coronary Syndrome (ACS) with admission plasma glucose (APG) e" $7.8 \mathrm{mmol} / \mathrm{L}$, admitted in the coronary care unit, DMCH, Dhaka within the study period were taken as sampling population. Patients with structural heart disease (i.e. congenital heart disease, valvular heart disease, cardiomyopathy etc), patients with previously diagnosed case of Diabetes mellitus (with or without taking ant-diabetic drugs), patients with ongoing treatment with glucocorticoids or immunosuppressive agents, patients with serious co-morbid conditions (i.e. CKD, CLD, Malignancy) and unwilling to participate were excluded from the study. Sampling technique was purposive and sample size was 157. Informed consent was taken from each patient or from legal guardian. Initial evaluation of patients was performed by history and clinical examination. The diagnosis of acute coronary syndrome (ACS) was done by identifying the triad of clinical presentation (including a history of coronary artery disease), electrocardiographic changes and biochemical cardiac markers. Then APG level was tested for each patient. Baseline investigation e.g., serum creatinine, fasting lipid profile, echocardiography was done for each patients. Subsequent blood sample was taken for HbA1c. Pre-discharge OGTT was performed according to a standardized protocol with $75 \mathrm{gm}$ glucose. Five ml venous blood was drawn by sterile disposable plastic syringe with aseptic precaution from ante-cubital vein of the subjects by a specified person. Collected blood was kept in test tubes without any anti-coagulant and labeled. Then specimens were sent to the department of Biochemistry/Clinical pathology, Dhaka Medical College Hospital. APG, fasting plasma glucose (FPG), OGTT were done by enzymatic method by AE-30F machine (made by China). HbA1c were done by enzymatic method by Nycocard reader II (made by China). APG, FPG, HbA1c was compared with pre-discharge OGTT for detecting undiagnosed diabetes in ACS patients with admission hyperglycaemia. All the information was properly noted in the preformed data collection sheet. Data was analyzed by using SPSS (statistical package for the social science) version 16.0. Continuous data were expressed as mean \pm standard deviation of mean and categorical data as percentages. Test statistics to be used to analyze the data are descriptive statistics, Chi square test, and analysis of variance. Level of significance was set at 0.05 . 


\section{Results:}

The study enrolled 157 patients of ACS with admission hyperglycaemia but without known diabetes mellitus. The objective of the study was to compare the performance of APG level, FPG level and $\mathrm{HbA} 1 \mathrm{c}$ to diagnose diabetes mellitus considering pre-discharge OGTT levels as a gold standard. The findings of the study are in tables.

\section{Table-I}

Age \& sex distribution of the study subjects. $(n=157)$.

\begin{tabular}{lccc}
\hline Age (in year) & $\begin{array}{c}\text { Total } \\
\text { Subjects } \\
(\mathrm{n}=157)\end{array}$ & $\begin{array}{c}\text { Male } \\
(\mathrm{n}=120)\end{array}$ & $\begin{array}{c}\text { Female } \\
(\mathrm{n}=37)\end{array}$ \\
\hline Mean $\pm \mathrm{SD}$ & $60.61 \pm 15.7$ & $60.40 \pm 16.19$ & $61.29 \pm 14.20$ \\
Median & $60(35-90)$ & $62(35-90)$ & $60(36-82)$ \\
(Range) & & & \\
\hline
\end{tabular}

Table-1 shows age distribution of study subjects. Of total 157 study subjects 120 (76.3\%) were male and $37(23.7 \%)$ were female. Age range of the study subjects was $35-90$ years with mean $( \pm \mathrm{SD})$ age 60.61 $( \pm 15.7)$ yrs and median age 60 years.

\section{Table-II}

Distribution of traditional risk factors among the study subjects $(n=157)$.

\begin{tabular}{lccc}
\hline \multicolumn{4}{c}{ OGTT classification $(\mathrm{n}=157)$} \\
$\begin{array}{l}\text { Traditional } \\
\text { risk factor }\end{array}$ & $\begin{array}{c}\text { Non-diabetic } \\
\text { \& IGH } \\
(\mathrm{n}=100)\end{array}$ & $\begin{array}{c}\text { Diabetic } \\
(\mathrm{n}=57)\end{array}$ & $\begin{array}{c}\text { Total } \\
(\mathrm{n}=157)\end{array}$ \\
\hline Smoking & $67(67.0 \%)$ & $42(73.6 \%)$ & $109(69.42 \%)$ \\
Hypertension & $58(58.0 \%)$ & $39(68.4 \%)$ & $97(61.8 \%)$ \\
$\begin{array}{l}\text { Family history } \\
\text { of premature }\end{array}$ & $18(18.0 \%)$ & $22(38.6 \%)$ & $40(25.47 \%)$ \\
CAD & & & \\
$\begin{array}{l}\text { Dyslipidaemia } \\
\text { Obesity }\end{array}$ & $63(63.0 \%)$ & $48(84.2 \%)$ & $111(70.7 \%)$ \\
\hline
\end{tabular}

Distribution of traditional risk factors revealed that the prevalence of dyslipidaemia was quite high (70.7\%), it was more in diabetic patients $(84.2 \%)$ than in non-diabetic patients (63\%). Smoking was also more prevalent in diabetic group than in nondiabetic group (73.6\% vs $67 \%$ ) \& total prevalence was $69.42 \%$. Prevalence of hypertension was present in $61.8 \%$ in study subjects, $58.0 \%$ in nondiabetic and $68.4 \%$ in diabetic group.

\section{Table-III}

Distribution of patients by OGTT $(n=157)$.

\begin{tabular}{lc}
\hline OGTT Classification & Frequency (\%) \\
\hline Diabetic & $57(36.3)$ \\
Non-diabetic (Including & $100(63.7)$ \\
$\begin{array}{ll}\text { Impaired glucose homeostasis-IGH } \\
\& \text { normal glucose metabolism) }\end{array}$ & \\
\hline
\end{tabular}

Table III shows OGTT revealed 57(36.3\%) patients were diabetic and 100(63.7\%) were non-diabetic. Among the non-diabetic patients 52 (33.12\%) patients had impaired glucose metabolism and 48 (30.57\%) patients had normal glucose metabolism (table III).

\section{Table-IV}

Distribution of study subjects according to admission plasma glucose (APG) level $(n=157)$.

\begin{tabular}{lcc}
\hline $\begin{array}{l}\text { Admission plasma } \\
\text { glucose (APG) }\end{array}$ & Frequency & Percentage \\
level $(\mathrm{mmol} / \mathrm{l})$ & & \\
\hline $\begin{array}{l}\text { Non-diabetic }(<11.1 \mathrm{mmol} / \mathrm{l} \\
\text { but }>7.8 \mathrm{mmol} / \mathrm{l})\end{array}$ & 128 & 81.3 \\
Diabetic $(>11.1 \mathrm{mmol} / \mathrm{l})$ & 29 & 18.5 \\
\hline
\end{tabular}

Table-IV shows according to admission plasma glucose level 29 (18.5\%) patients were diabetic with admission plasma glucose level e" $11.1 \mathrm{mmol} / \mathrm{l}$ and $128(81.3 \%)$ patients were non-diabetic with admission plasma glucose level $<11.1 \mathrm{mmol} / \mathrm{l}$ (Table-IV).

\section{Table-V}

Distribution of study subjects according to fasting plasma glucose (FPG) level ( $n=157)$.

\begin{tabular}{|c|c|c|}
\hline $\begin{array}{l}\text { Fasting plasma } \\
\text { glucose (FPG) } \\
\text { level (mmol/l) }\end{array}$ & Frequency & Percentage \\
\hline $\begin{array}{l}\text { Non-diabetic FPG } \\
(<6.0 \mathrm{mmol} / \mathrm{l})\end{array}$ & 94 & 59.87 \\
\hline $\begin{array}{l}\text { Impaired FPG } \\
(6.1-6.9 \mathrm{mmol} / \mathrm{l})\end{array}$ & 21 & 13.37 \\
\hline $\begin{array}{l}\text { Diabetic FPG } \\
(>7.0 \mathrm{mmol} / \mathrm{l})\end{array}$ & 42 & 26.75 \\
\hline
\end{tabular}

Table-V shows according to fasting plasma glucose (FPG) level 94(59.87\%) patients were non-diabetic, 21(13.37\%) had impaired FPG and 42(26.75\%) had diabetes (Table-V). 
Table-VI

Distribution of study subjects according to HbA1c level ( $n=157)$.

\begin{tabular}{lcc}
\hline HbA1c level (\%) & Frequency & Percentage \\
\hline Non-diabetic [HbA1c level (<6.5\%)] & 111 & 70.70 \\
Diabetic [HbA1c level $(\geq 6.5 \%)]$ & 46 & 29.30 \\
\hline
\end{tabular}

Table-VII

Comparison of FPG, APG and HbA1c level among study subjects when stratified with OGTT ( $n=157)$.

\begin{tabular}{lcccc}
\hline Tests & $\begin{array}{c}\text { Total }(\mathrm{n}=157) \\
\text { Mean } \pm \text { SD }(\text { range })\end{array}$ & $\begin{array}{c}\text { Non-diabetic }(\mathrm{n}=100) \\
\text { Mean } \pm \text { SD }\end{array}$ & $\begin{array}{c}\text { Diabetic }(\mathrm{n}=57) \\
\text { Mean } \pm \text { SD }\end{array}$ & p value \\
\hline $\begin{array}{l}\text { Fasting plasma glucose } \\
\text { (FPG) }(\text { mmol/l) }\end{array}$ & $6.26 \pm 1.94(3.7-12.10)$ & $5.36 \pm 1.18$ & $7.84 \pm 2.01$ & $<0.001$ \\
$\begin{array}{l}\text { Admission plasma glucose } \\
\text { (APG) (mmol/l) }\end{array}$ & $9.64 \pm 2.02(7.80-18.0)$ & $9.17 \pm 1.92$ & $10.47 \pm 1.94$ & $<0.001$ \\
HbA1c $(\%)$ & $6.22 \pm 1.56(3.54-11.28)$ & $5.51 \pm 0.92$ & $7.45 \pm 1.69$ & $<0.001$ \\
\hline
\end{tabular}

$\mathrm{p}$ value derived from Student $\mathrm{t}$ test

Table-VIII

Comparison of performance of different diagnostic methods for diagnosing diabetes in relation to OGTT.

\begin{tabular}{|c|c|c|c|c|c|c|c|c|c|}
\hline & \multicolumn{2}{|c|}{$\begin{array}{l}\text { Fasting plasma } \\
\text { glucose }\end{array}$} & \multicolumn{2}{|c|}{$\begin{array}{c}\text { HbA1c } \\
\text { level (\%) }\end{array}$} & \multicolumn{2}{|c|}{$\begin{array}{c}\text { Admission plasma } \\
\text { glucose }\end{array}$} & \multicolumn{2}{|c|}{$\begin{array}{c}\text { Combined FPG } \\
\text { and } \mathrm{HbA} 1 \mathrm{c}\end{array}$} & \multirow[t]{2}{*}{ Total } \\
\hline & $\begin{array}{l}\geq 7.0 \\
\mathrm{mmol} / \mathrm{l}\end{array}$ & $\begin{array}{c}<7.0 \\
\mathrm{mmol} / \mathrm{l}\end{array}$ & $\geq 6.5 \%$ & $<6.5 \%$ & $\begin{array}{l}\geq 11.1 \\
\mathrm{mmol} / \mathrm{l}\end{array}$ & $\begin{array}{l}<11.1 \\
\mathrm{mmol} / \mathrm{l}\end{array}$ & $\begin{array}{c}\mathrm{FPG} \\
\geq 7.0 \mathrm{mmol} / \mathrm{l} \\
\text { and/or } \\
\text { HbA1c level } \\
\geq 6.5 \%\end{array}$ & $\begin{array}{c}\quad \mathrm{FPG} \\
<7.0 \mathrm{mmol} / \mathrm{l} \\
\text { and HbA1c } \\
\text { level } \\
<6.5 \% \\
\end{array}$ & \\
\hline Diabetes (by OGTT) & $38(\mathrm{TP})$ & $19(\mathrm{FN})$ & $41(\mathrm{TP})$ & $16(\mathrm{FN})$ & $17(\mathrm{TP})$ & $40(\mathrm{FN})$ & $45(\mathrm{TP})$ & $12(\mathrm{FN})$ & 57 \\
\hline Non-diabetes (by OGTT) & $4(\mathrm{FP})$ & $96(\mathrm{TN})$ & $05(\mathrm{FP})$ & $95(\mathrm{TN})$ & $12(\mathrm{FP})$ & $88(\mathrm{TN})$ & $9(\mathrm{FP})$ & $91(\mathrm{TN})$ & 100 \\
\hline Total & 42 & 115 & 46 & 111 & 29 & 128 & 54 & 103 & 157 \\
\hline
\end{tabular}

Table- IX

Performance of FPG, APG and HbA1c in the diagnosis of DM in patients with ACS with admission hyperglycemia when OGTT is the gold standard.

\begin{tabular}{lcccccc}
\hline Test & Prevalence & Sensitivity & Specificity & PPV & NPV & Accuracy \\
\hline APG & 18.47 & 29.82 & 88.00 & 58.62 & 68.75 & 66.87 \\
FPG & 26.75 & 66.67 & 96.00 & 90.42 & 83.47 & 85.33 \\
HbA1c & 29.30 & 71.92 & 95.00 & 89.13 & 85.58 & 86.62 \\
Combined FPG & 34.39 & 78.94 & 91.00 & 83.33 & 88.34 & 86.62 \\
and HbA1c & & & & & & \\
\hline
\end{tabular}


Table-VI shows according to HbA1c level diabetes was diagnosed in 46(29.30\%) patients and 111 (70.70\%) had non-diabetic normal HbA1c level (Table-VI).

Table- VII shows the mean $( \pm \mathrm{SD})$ value of FPG, $\mathrm{APG}$ and $\mathrm{HbA1c}(\%)$ were $7.84 \pm 2.01 \mathrm{mmol} / \mathrm{l}$, $10.47 \pm 1.94 \mathrm{mmol} / \mathrm{l}$ and $7.45 \pm 1.69 \mathrm{mmol} / \mathrm{l}$ respectively in patients who were found to be diabetic by OGTT and $5.36 \pm 1.18 \mathrm{mmol} / \mathrm{l}, 9.17 \pm 1.92$ $\mathrm{mmol} / \mathrm{l}$ and $5.51 \pm 0.92 \mathrm{mmol} / \mathrm{l}$ respectively in patients who were found to be non-diabetic by OGTT. The mean FPG $(p<0.001)$, APG $(p<0.001)$ and $\mathrm{HbA1C}(\mathrm{p}<0.001)$ of diabetic patients were significantly higher than non-diabetic patients (Table- VII).

Table- IX shows the prevalence of diabetes according to OGTT was $36.31 \%$ (57/157). The prevalence of diabetes according to APG, FPG, $\mathrm{HbA} 1 \mathrm{c}$ and combined FPG and HbA1c were $18.47 \%, 26.75 \%, 29.30 \%$ and $34.39 \%$ respectively. The sensitivity of APG, FPG, HbA1c and combined FPG and HbA1c were $29.82 \%, 66.67 \%, 71.92 \%$ and $78.94 \%$ respectively. The specificity of APG, FPG, $\mathrm{HbA} 1 \mathrm{c}$ and combined FPG and HbA1c were $88.00 \%, 96.00 \%, 95.00 \%$ and $91.00 \%$ respectively. The PPV of APG, FPG, HbA1c and combined FPG and $\mathrm{HbA} 1 \mathrm{c}$ were $58.62 \%, 90.42 \%, 89.13 \%$ and $83.33 \%$ respectively.

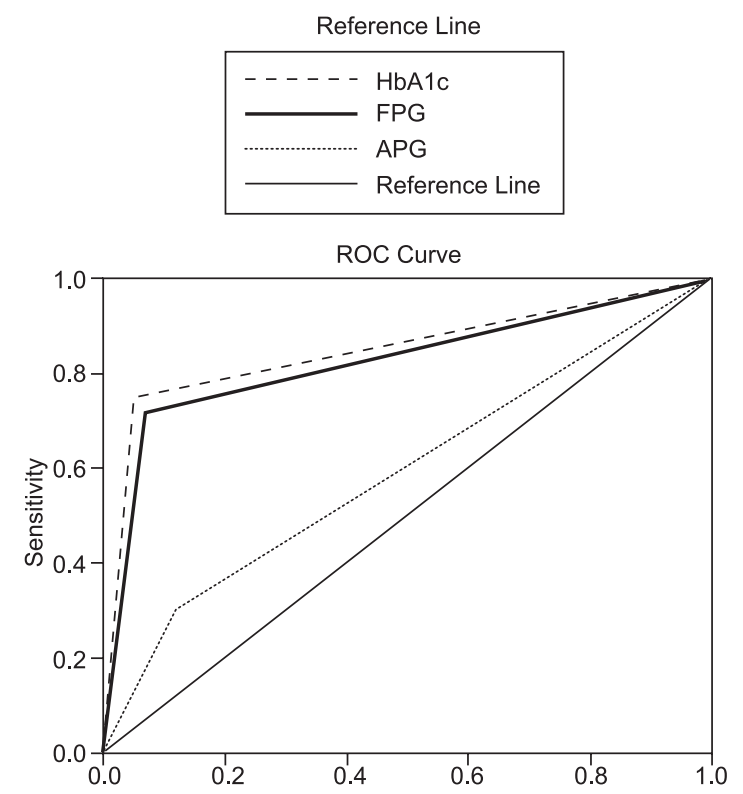

Fig 1: Receiver operating characteristic (ROC) curves comparing different diagnostic methods for diabetes.
Fig 1 compares different diagnostic methods for diabetes. The OGTT result was used as the reference. The area under the curve was 0.589 for admission plasma glucose, 0.825 for fasting plasma glucose and 0.852 for $\mathrm{HbA1c}$.

\section{Discussion:}

\section{Detecting abnormal glucose metabolism}

For decades, the diagnosis of diabetes was based on plasma glucose criteria, either the fasting plasma glucose (FPG) or the 2 -h value in the 75 -g OGTT. In 2009, an International Expert Committee that included representatives of the ADA, the International Diabetes Federation (IDF), and the EASD recommended the use of the $\mathrm{HbA1C}$ test to diagnose diabetes, with a threshold of e" $6.5 \%$, and the ADA adopted this criterion in 2010.

Which of these is most appropriate for detecting undiagnosed diabetes in the setting of ACS remains to be clearly defined? The HbA1c has several advantages to the FPG and OGTT, including greater convenience (since fasting is not required), evidence to suggest greater pre analytical stability, and less day-to-day perturbations during periods of stress and illness. These advantages must be balanced by greater cost, the limited availability of $\mathrm{HbA} 1 \mathrm{c}$ testing in certain regions of the developing world, and the incomplete correlation between $\mathrm{HbA} 1 \mathrm{c}$ and average glucose in certain individuals. ${ }^{12}$

\section{Diabetes Mellitus and Coronary Heart Disease}

Diabetes mellitus has an important impact on vascular disease. About three-quarters of diabetic patients die from cardiovascular disease and twothirds of these die from the manifestations of ischemic heart disease, promoting coronary artery disease to be the leading cause of morbidity and mortality in patients with diabetes mellitus. ${ }^{13}$

Patients with diabetes are more likely to experience acute myocardial infarction (AMI) and heart failure, and are at a greater risk of dying from an acute cardiac event than patients without diabetes. These differences may be related to the severity and extent of coronary heart disease in diabetic patients, the extent of left ventricular remodeling, and the presence of significant ventricular arrhythmias. However, the main reason for increased pre hospital, hospital and 1- 
year post-hospital mortality in diabetic patients is the development of heart failure after AMI. Sudden death and fatal ventricular arrhythmias contribute to a lesser extent to the increased mortality rate. ${ }^{13}$

\section{Nondiabetic Glucose Disturbances and Acute Coronary Syndromes}

Hyperglycemia may also occur in patients without prior history of diabetes. In some, it is transient and may normalize in the following days (therefore called 'stress hyperglycemia'), but in others it is persistent reflecting the presence of diabetes mellitus. Stress hyperglycemia is not an event exclusively specific for ACS. In almost all states of acute illness, blood glucose levels may be elevated. Despite the fact that stress hyperglycemia is a common event, but it still lacks a widely accepted definition. Most authors consider hospital admission plasma glucose as a relevant finding, but the threshold value for stress induced elevated plasma glucose is still under dispute. However, most authors simply use definitions of non-stress hyperglycemia, according to ADA or WHO guideline. ${ }^{13}$

Stress hyperglycemia during critical illness has long been considered essential to provide fuel for vital organs and hence was interpreted as a beneficial adaptation. Evidence is now growing against this notion as hyperglycemia is identified as an independent risk factor for adverse outcome of numerous surgical and medical conditions, and avoiding hyperglycemia with intensive therapy has been shown to improve the outcome. ${ }^{13}$

Some prospective studies have reported on abnormal glucose metabolism in patients with cardiovascular disease. The Glucose tolerance in patients with Acute Myocardial Infarction (GAMI) study was designed to detect the prevalence of dysglycaemia in patients admitted to hospital with AMI. An OGTT was performed at hospital discharge, about four to five days after the MI $(n=164)$, and again three months later $(n=144)$. Abnormal glucose metabolism was detected in approximately two thirds of patients at hospital discharge $-35 \%$ had prediabetes and $31 \%$ newly diagnosed T2DM. A similar prevalence was recorded three months later, suggesting that increased sympathetic drive induced by the acute illness was not the main reason for the metabolic imbalance, and that testing before discharge from hospital provided an accurate reflection of the glucometabolic status. ${ }^{14}$

The present study showed that despite having admission hyperglycaemia only $36.30 \%$ (57 out of 157) patients were found to be truly diabetic by OGTT, $33.12 \%$ (52 out of 157 ) patients had impaired glucose homeostasis and $30.57 \%$ (48 out of 157) patients had normal glucose metabolism. De Mulder et al found ${ }^{6}$ that diabetes was present in $35 \%$ patients, impaired glucose homeostasis was found in $44 \%$ patients and only $21 \%$ patients had normal glucose metabolism despite admission hyperglycaemia. In their study $\mathrm{Hu}, \mathrm{Pan}$ and $\mathrm{Yu}$ too $^{15}$ showed that by OGTT only $26.9 \%$ subjects were found to have type 2 diabetes in patients with ACS and unknown sugar status but with admission hyperglycaemia.

In our study APG labelled 29 (81.3\%) patients as diabetic and 128 (18.5\%) patients as non-diabetic (cut off value was $\geq 11.1 \mathrm{mmol} / \mathrm{l}$ ). Out of 29 patients diagnosed as diabetes, gold standard test OGTT diagnosed 17 patients as true diabetic (true positive) and 12 as non-diabetic (false positive). Out of 128 nondiabetic patients, OGTT diagnosed 40 patients as having diabetes (false negative) and 88 patients as non-diabetic (true negative).The sensitivity, specificity, positive predictive value (PPV) and negative predictive value (NPV) were $29.82 \%, 88 \%$, $58.62 \%$ and 68.75 respectively. This finding was supported by Okosieme et al., who studied 140 patients with a diagnosis of acute coronary syndrome with admission hyperglycaemia. In their study sensitivity, specificity, and PPV for diagnosing diabetes with APG were $65.8 \%, 83.3 \%$ and $59.5 \%$ respectively. ${ }^{16}$ De Mulder et $\mathrm{al}^{6}$ found that sensitivity was $16 \%$ and specificity $89 \%$. The sensitivity of our study was $29.82 \%$ which is much lower than the findings of Okosieme et al.but higher than the findings of De Mulder et al. The specificity of our study was $88 \%$ which was similar to both the studies.

In our study according to FPG level 94 (59.9\%) patients were normal, 21 (13.37\%) had impaired fasting glucose and $42(26.75 \%)$ had diabetes. With an FPG of $\geq 7.0 \mathrm{mmol} / \mathrm{l}$ as a diagnostic cut-off, out of 42 diabetic positive patients, gold standard test OGTT diagnosed 38 patients as truly diabetic (true positive) and 4 patients as non-diabetic (false positive). Out of 115 diabetes negative patients, 
OGTT diagnosed 19 patients as having diabetes (false negative) and 96 as non-diabetic (true negative). The sensitivity, specificity, PPV and NPV were $66.67 \%, 96 \%, 90.42 \%$ and $83.47 \%$ respectively. Similarly De Mulder et $\mathrm{al}^{6}$ showed in their study only $36.84 \%$ (14 of 38) of ACS patients with admission hyperglycaemia were truly diabetic. They showed the sensitivity of $37 \%$ and specificity of $100 \%$. Our observation is also consistent with the findings of Okosieme et al. They found that the sensitivity, specificity and PPV for diagnosing diabetes with FPG were $81.6 \%, 64.7 \%$ and $46.3 \%$ respectively. ${ }^{16}$

According to HbA1c level diabetes was diagnosed in $46(29.30 \%)$ patients and $111(70.70 \%)$ had normal HbA1c level. Considering HbA1c level e" $6.5 \%$ as the diagnostic cut-off, out of 46 patients diagnosed as diabetes, gold standard test OGTT diagnosed 41 patients as true diabetic (true positive) and 05 patients as non-diabetic (false positive). Out of 111 non-diabetic patients, OGTT diagnosed 16 patients as having diabetes (false negative) and 95 as non-diabetic (true negative). The sensitivity, specificity, PPV and NPV were $71.92 \%, 95 \%$, $89.13 \%$, were $85.58 \%$ respectively. This observation is consistent with the observation of De Mulder et al. In that study considering $\mathrm{HbA} 1 \mathrm{c}$ level $\geq 6.5 \%$ as the diagnostic cut-off, $29 \%$ of the 38 patients with previously undiagnosed diabetes were detected as diabetic. ${ }^{6}$

Combined FPG \& HbA1c level diagnosed 54 (34.39\%) patients as diabetic and 103 patients as non-diabetic (cut off value was $\mathrm{FPG} \geq 7.0 \mathrm{mmol} / \mathrm{l}$ and/or HbA1c $\geq 6.5 \% \mathrm{l})$. Out of 54 patients diagnosed as diabetes, gold standard test OGTT diagnosed 45 patients as true diabetic (true positive) and 9 patients as non-diabetic (false positive). Out of 103 non-diabetic patients, OGTT diagnosed 12 patients as having diabetes (false negative) and 91 as nondiabetic (true negative) The sensitivity, specificity, PPV and NPV of combined FPG \& HbA1c were $78.94 \%, 91 \%, 83.33 \%$ and $88.34 \%$ respectively .Our observation was consistent with $\mathrm{Hu}$ et al, they found that combined use of FPG \& HbA1c yield sensitivity of $87.9 \%$ and specificity of $82.4 \%$ for detecting undiagnosed diabetes. ${ }^{17}$

Although, neither FPG, APG nor HbA1c level were as good as OGTT in detecting true diabetes, but combined FPG \& HbA1c were found to be more sensitive screening tool for detecting unknown diabetes in ACS patients with admission hyperglycaemia.

Conclusion: In comparison to FPG or HbA1c or APG alone, the combined use of FPG \& HbA1c might be a more sensitive \& specific screening tool for identifying high risk individuals like ACS patients with previously unknown glucose status but with admission hyperglycaemia. However for detecting DM in a stressful state like ACS patients, OGTT is still by far the best.

\section{Conflict of Interest - None.}

\section{References:}

1. Bartnik M, Ryden L, Ferrari R, Malmberg K, Pyörälä $\mathrm{K}$, Simoons $\mathrm{M}$ et al. The prevalence of abnormal glucose regulation in patients with coronary artery disease across Europe .The Euro Heart Survey on diabetes and the heart. Eur Heart $J$ 2004; 25: 1880-1890.

2. Wascher TC, Sourij H, Roth M, Dittrich P. Prevalence of pathological glucose metabolism in patients undergoing elective coronary angiography. Atherosclerosis 2004; 176(2):419-421.

3. Mathers C, Bernard C, Iburg K, et al. Global burden of disease in 2002: data sources, methods and results. Geneva: World Health Organisation 2003:47.

4. Shaw JE, Sicree RA, Zimmet PZ. Global estimates of the prevalence of diabetes for 2010 and 2030. Diabetes Res Clin Pract 2010; 87:4-14.

5. Bolk J, Van der Plog T, Cornel JH, Arnold AE, Sepers J, Umans VA. Impaired glucose metabolism predicts mortality after a myocardial infarction. Int $J$ Cardiol 2001; 79:207-214.

6. de Mulder M, Oemrawsingh RM, Stam F, Boersma E, Umans VA et al. Comparison of diagnostic criteria to detect undiagnosed diabetes in hyperglycaemic patients with acute coronary syndrome. Heart 2012; 98:37-41.

7. Capes SE, Hunt D, Malmberg K and Gerstein HC. Stress hyperglycaemia and increased risk of death after myocardial infarction in patients with and without diabetes: a systematic overview. Lancet 2000; 355 : 773-778.

8. de Mulder M, Cornel JH, van der Ploeg T, Boersma E, Umans VA. Elevated admission glucose is associated with increased long-term mortality in myocardial infarction patients, irrespective of the initially applied reperfusion strategy. Am Heart J 2010; 0160(3):412419.

9. de Mulder M, Oemrawsingh RM, Stam F, Boersma E, Umans VA et al. Current management of hyperglycemia in acute coronary syndromes: a national Dutch survey. Crit Pathw Cardiol 2009; 8(2):66-70. 
10. Anantharaman R, Heatley M, Weston CF. Hyperglycaemia in acute coronary syndromes: riskmarker or therapeutic target? Heart 2009; 95:697-703.

11. Ryden L, Standl E, Bartnik M, Betteridge J, de Boer $\mathrm{MJ}$, Cosentino $\mathrm{F}$ et al . Guidelines on diabetes, prediabetes, and cardiovascular diseases: executive summary. The Task Force on Diabetes and Cardiovascular Diseases of the European Society of Cardiology (ESC) and of the European Association for the Study of Diabetes EASD. Eur Heart J 2007; 28:88136.

12. American Diabetic Association. Standards of Medical Care in Diabetes 2013. Diabetes Care 2013; 36:11-66.

13. Altabas V, Altabas K, Cigrovski MB, Sanja Maloševac, Vrkljan M, Heitzler VN. Glucose Metabolism Disorders In Patients With Acute Coronary Syndromes. Acta Clin Croat 2011; 51:71-77.
14. Anselmino M, Wallander M, Norhammar A, Mellbin L, Rydén L. Implications of abnormal glucose metabolism in patients with coronary artery disease. Diabetes Vasc Dis Res 2008; 5(4):285-290.

15. Hu DY, Pan CY, Yu JM. The relationship between coronary artery disease and abnormal glucose regulation in China: the China Heart Survey. Eur Heart $J$ 2006; 27:2573- 2579.

16. Okosieme OE, Peter R, Usman M, Bolusani H, Suruliram P, George L et al. Can Admission and Fasting Glucose Reliably Identify Undiagnosed Diabetes in Patients With Acute Coronary Syndrome? Diabetes Care 2008; 31:1955-1959.

17. Hu Y, Liu W, Chen Y, Zhang M, Wang L, Zhou H et al. Combined use of fasting plasma glucose and glycated hemoglobin A1c in the screening of diabetes and impaired glucose tolerance. Acta Diabetol 2010; 47:231-236. 